\title{
Clinical use of biologics in vasculitis syndromes
}

This article was published in the following Dove Press journal:

Biologics:Targets and Therapy

24 October 2012

Number of times this article has been viewed

\section{Marino Paroli \\ Division of Clinical Immunology and Rheumatology, Department of Biotechnology and Medical-Surgical Sciences, Sapienza University of Rome, Italy}

Correspondence: Marino Paroli Sapienza University of Rome, Piazzale Aldo Moro 5, 00161 Roma, Italy Tel +390773476814

Fax +3907734768I3

Email marino.paroli@uniromal.it
Abstract: Vasculitis syndromes are relative rare conditions but can cause significant mortality and morbidity if not treated adequately. Recent advances in immunosuppressant therapy have radically changed the course of these diseases. However, the standard therapy is not always well tolerated by patients, and some cases are refractory to treatment. New therapeutic possibilities have emerged with the use of so-called "biologics," a new class of genetically engineered drugs used for inflammatory rheumatic diseases, including rheumatoid arthritis, ankylosing spondylitis, and psoriatic arthritis. In the present review, summarized are the most recent data on the efficacy and safety of biologics in the treatment of vasculitis syndromes that cannot be treated with standard therapy.

Keywords: anti-TNF-alpha, rituximab, tocilizumab, vasculitides

\section{Introduction}

Vasculitis syndromes are a heterogeneous group of diseases characterized by the inflammation of the vessel wall. The consequence of vasculitis depends on the size and number of vessels involved. Potentially, any organ can be damaged, mainly the brain, liver, skin, gut, and kidney. Vasculitides may be classified in large- and medium-vessel vasculitides, which include polymyalgia rheumatica (PMR), giant cell arteritis (GCA), Takayasu arteritis (TA), polyarteritis nodosa (PAN), Kawasaki disease (KD), and small-vessel vasculitides, including antineutrophil cytoplasmic antibodies (ANCA)associated vasculitides (AAVs) and Henoch-Shonlein purpura. The AAVs include Wegener's granulomatosis (WG), now defined as granulomatosis with polyangiitis (GPA), Churg-Strauss syndrome, and microscopic polyangiitis (MPA). ${ }^{1-3}$

Biologics currently used in the treatment of inflammatory rheumatic diseases include anti-TNF-alpha agents (infliximab, etanercept, adalimumab, golimumab, and certolizumab), anti-interleukin (IL)-6-receptor antibody (tocilizumab), and anti-CD20 antibody (rituximab). These drugs are highly efficacious in treating the rheumatic diseases, although they can expose patients to an increased risk of severe infection. The present review summarizes the most recent findings on the use of these agents in the treatment of the different types of vasculitides.

\section{Large- and medium-vessel vasculitides}

Large-vessel vasculitides include a number of diseases ultimately affecting more-vital organs, and are potentially lethal. They include PMR, GCA, TA, KD, and polyarteritis nodosa. submit your manuscript | www.dovepress.com

Dovepress

http://dx.doi.org/10.2147/BTT.S37537 which permits unrestricted noncommercial use, provided the original work is properly cited. 


\section{Anti-TNF-alpha agents}

Anti-TNF-alpha agents are the most widely used drugs for treating inflammatory rheumatic diseases. The rationale for their use in vasculitides relies on the fact that some studies have shown an increased concentration of tumor necrosis factor (TNF) in patients with different forms of vascular inflammation. ${ }^{4,5} \mathrm{~A}$ recent large study ${ }^{6}$ retrospectively analyzed 99 patients with PMR included in different studies and treated with anti-TNF-alpha. Infliximab (IFX) was the anti-TNFalpha of choice in three studies, while etanercept (ETA) was in five. After anti-TNF-alpha treatment, prednisone reduction was observed in all studies. Clinical improvement was found in seven of seven studies, and laboratory improvement in at least $50 \%$ of inflammatory markers was observed in six of seven studies. This study demonstrated good clinical and laboratory response to anti-TNF-alpha therapy in patients with PMR, with or without glucocorticoid.

In another recent report, ${ }^{7}$ a 69-year-old woman was initially diagnosed as having PMR. Prednisone was progressively tapered to complete discontinuation a year and a half after PMR diagnosis. However, at that time, she started to complain of asthenia, abdominal cramping and pain on the left side, weight loss, and bloody diarrhea. A colonoscopy confirmed a diagnosis of left-sided ulcerative colitis (UC). Treatment with the anti-TNF-alpha adalimumab (ADA), $40 \mathrm{mg}$ every 2 weeks subcutaneously along with prednisone, yielded rapid improvement of symptoms. This report highlights the beneficial effect of TNF-antagonists in vasculitis associated with UC. In another study, a case has been reported of a patient who had been initially diagnosed as having PMR. Because of refractory disease, treatment with ADA (40 mg every 2 weeks subcutaneously) along with prednisone and methotrexate (MTX) was initiated, yielding progressive improvement of symptoms and normalization of laboratory abnormalities. ${ }^{8}$

In a study on $\mathrm{TA},{ }^{9} 84$ patients (five personal cases and 79 patients from the literature) with refractory disease treated with anti-TNF-alpha were analyzed. All patients, except one, were inadequately controlled with other immunosuppressive regimens before anti-TNFalpha therapy. The first-line administration of anti-TNFalpha included 81\% (68/84) IFX and 19\% (16/84) ETA. Most patients received $5 \mathrm{mg} / \mathrm{kg}$ IFX combined with MTX or azathioprine. Thirty-one of $84(37 \%)$ patients achieved a complete remission, and $45(53.5 \%)$ were partial responders. There were eight $(9.5 \%)$ nonresponders in all. Twenty-seven of $84(32 \%)$ patients needed to increase the dose of anti-TNF-alpha because of uncontrolled disease, and $15(18 \%)$ needed to switch to anti-TNF-alpha. The authors concluded that anti-TNF-alpha agents were an efficient therapy in refractory TA patients, although side effects (mainly infections) were observed in $20 \%$ of cases.

However, conflicting results on anti-TNF-alpha efficacy for TA have been also reported. Osman et $\mathrm{al}^{10}$ described two patients with TA: one with progressive TA despite management with two different anti-TNF-alpha agents, IFX and ADA, and another who developed TA while treated with IFX for the management of preexisting Crohn's disease. Their observations suggest that a multicenter, randomized study should be designed to assess the extent of resistance to these agents for managing TA.

Anti-TNF-alpha agents have been also tested in KD. IFX was administered successfully to a 1-month-old girl with refractory KD. ${ }^{11}$ Response to anti-TNF-alpha therapy was also observed in another study, ${ }^{12}$ in which cessation of fever occurred in 13 of $16 \mathrm{KD}$ patients. There were no infusion reactions to IFX and no complications attributed to IFX administration in any of the treated patients. The authors concluded that the success of TNF-alpha blockade in this small series of patients suggested a central role for TNF-alpha in $\mathrm{KD}$ pathogenesis. Conclusively, in consideration of the results reported here, anti-TNF-alpha does not appear at present to be an advisable treatment for large-vessel vasculitis syndromes, with the exception of a few selected cases. Further data from randomized controlled trials are urgently needed to clarify the role of anti-TNF-alpha in the therapy for these conditions.

\section{Tocilizumab}

Interleukin-6 (IL-6) plays a key role in inflammatory diseases. IL-6 multiple activities include the induction of antibody production, activation of Th17 cells, and increase of hepcidin, which is responsible for anemia and blast-cell colony formation. It is also involved in inflammation following cardiac injury. ${ }^{13-16}$ Tocilizumab (TCZ) is a humanized antihuman IL-6 receptor monoclonal antibody designed to block IL-6 signaling. It has been approved in both the USA and EU for the treatment of rheumatoid arthritis. The rationale for its use in the treatment of vasculitis syndromes is corroborated by several experimental pieces of evidence., ${ }^{417-24}$

In a relatively old study, ${ }^{25}$ anti-IL-6 receptor antibody TCZ was used to treat a 20-year-old woman with refractory, active TA complicated by UC. Treatment with TCZ improved the clinical manifestations of TA and the abnormal laboratory findings, and ameliorated the activity of UC. These results indicated that IL-6 receptor inhibition with TCZ might be an effective treatment option for TA. 
In a retrospective study, ${ }^{26}$ the outcomes of ten patients with relapsing/refractory GCA, TA, or PMR treated with TCZ were assessed. In particular, seven subjects had failed at least one second-line agent. The patients received treatment with $\mathrm{TCZ}$ for a mean period of 7.8 months (range: 4-12 months). All patients entered maintained clinical remission during TCZ therapy. The authors concluded that TCZ led to clinical and serological improvement in patients with refractory/relapsing GCA, TA, or PMR.

In a case report, ${ }^{27}$ a 28 -year-old patient with TA failed to respond to high doses of prednisone in combination with MTX, pulses of cyclophosphamide (CYC) and methylprednisolone, azathioprine, mycophenolate mofetil, and ADA. Monthly infusions of IFX $5 \mathrm{mg} / \mathrm{kg}$ were started for TCZ therapy (4-8 $\mathrm{mg} / \mathrm{kg}$ at monthly infusions). An impressive improvement in clinical and laboratory parameters of disease activity occurred, allowing the reduction of the prednisone dose from 30 to $5 \mathrm{mg} /$ day. However, after the eighth dose, the patient developed vascular disease progression in the aortic branches.

In another report, ${ }^{28}$ a patient with TA refractory to multiple conventional immunosuppressive agents and two TNF- $\alpha$ blockers was successfully treated with monthly TCZ infusions ( $8 \mathrm{mg} / \mathrm{kg}$ body weight) for 6 consecutive months. Clinical indices of disease activity, inflammatory markers and,${ }^{18}$ the findings from fluorodeoxyglucose positron emission/computerized tomography normalized, while the prednisone dosage was able to be tapered.

In another study, ${ }^{29}$ a 63 -year-old female diagnosed with PMR and started on corticosteroids could not be weaned off her steroid treatment. She was diagnosed with GCA with a temporal artery biopsy and ultrasound of the temporal and axillary arteries. She was then treated with TCZ, and even a after her first infusion, the patient reported an excellent response, with normalization of her inflammatory markers, allowing subsequent reduction of the prednisolone dosage.

In another case report, ${ }^{30}$ a 65 -year-old woman diagnosed with PMR was initially treated with prednisolone $(20 \mathrm{mg} /$ day $)$ followed by the prompt disappearance of clinical symptoms. But when prednisolone was tapered to $8-10 \mathrm{mg} /$ day, the disease flared repeatedly, and it was made worse by diabetes mellitus, hypertension, and osteoporosis. She was then treated with TCZ, and after five infusions, morning stiffness disappeared and disease remission ensued. Based on these data, TCZ appears to be a very promising biologic for the treatment of large-vessel vasculitides.

\section{Rituximab}

Rituximab (RTX) is a chimeric monoclonal antibody directed against the cell-surface protein CD20, which is selectively expressed on the B-lymphocyte lineage. ${ }^{31-37}$ The binding of RTX to CD20 causes the death of the target cell by different molecular and immunological mechanisms. Importantly, circulating B-cells remain undetectable in the peripheral blood for about 6-12 months following treatment with RTX. ${ }^{38}$ RTX is contraindicated in patients with active hepatitis B. Indeed, RTX-based treatment may induce increased significant replication of hepatitis B virus. ${ }^{39}$ Moreover, RTX must be used very cautiously in patients with hepatitis $\mathrm{C}$ virus (HCV)-related hepatitis. In this regard, recent data suggest that RTX-based therapies induce an increase in HCV expression in hepatic cells, which may become a target for a cell-mediated immune reaction after the withdrawal of treatment and restoration of immune control. Although $\mathrm{HCV}$-associated hepatic flares are frequently asymptomatic, life-threatening liver failure occurs in nearly $10 \%$ of cases. ${ }^{40}$

In a clinical study ${ }^{41}$ three patients with active refractory TA were treated with B-cell depletion therapy using RTX, followed by remission of the disease. In another study, ${ }^{42}$ a 6-year-old boy who had KD resistant to intravenous immunoglobulin and systemic steroids was treated with RTX, with rapid clinical, biological, and cardiac improvement. The treatment was also well tolerated.

RTX has also been found to be effective in polyarteritis nodosa. A case report of a 71-year-old $\operatorname{man}^{43}$ followed for polyarteritis nodosa and refractory to glucocorticoids and CYC was treated with RTX, with the subsequent disappearance of biological inflammation and regression of ischemic lesions in the upper limbs.

A case of severe life-threatening $\mathrm{HCV}$-associated polyarteritis nodosa successfully treated with RTX and a short course of corticosteroids without antiviral therapy has also been reported. The authors comment that this case, along with recently published data, emphasizes the value of B-cell-targeted therapy in this unusual form of $\mathrm{HCV}$-associated vasculitis. ${ }^{44}$

From these and other data, however, conclusive advice cannot yet be given to clinicians on the use of RTX in largevessel vasculitides, and further study is needed to assess the role of this biologic in clinical practice.

\section{Small-vessel vasculitides Anti-TNF-alpha}

Many concerns over the use of anti-TNF-alpha in AAV treatment have recently arisen. An association between 
therapeutic inhibition of TNF and solid malignancies was observed during the Wegener's Granulomatosis Etanercept Trial, which included 180 patients with GPA (Wegener's). Post-trial follow-up data ${ }^{45}$ were available for 153 patients ( $85 \%$ of the original cohort), with a median follow-up time of 43 months. Fifty percent of these patients had received ETA. There were no differences in demographic characteristics between the etanercept and placebo groups. Thirteen new solid malignancies were detected, eight in the etanercept group and five in the placebo group. Compared to the general population, the risk of solid malignancies in the ETA group was increased, but was not different from the risk in the placebo group compared to the general population (SIR 2.89 [95\% confidence interval 0.94-6.73]). All solid malignancies occurred in patients who had been exposed to CYC. The overall duration of disease and a history of malignancy before trial enrollment were associated with the development of malignancy during post-trial follow-up. It can be concluded, therefore, that the incidence of solid malignancies continued to increase during the long-term follow-up of Wegener's Granulomatosis Etanercept Trial cohort. However, this could not be attributed solely to ETA exposure during the trial. Anti-TNF-alpha therapy with ETA appears to further increase the risk of malignancy observed in patients with GPA treated with cytotoxic agents, and should be avoided in these patients.

A role for anti-TNF-alpha has also been proposed for mixed cryoglobulinemia (MC), which can be included among the autoimmune reactions in the course of $\mathrm{HCV}$ infection. As known, HCV is often associated with selfreactive immunity, which may complicate the course of the infectious disease. ${ }^{46}$

An interesting study ${ }^{47}$ was aimed at monitoring, prospectively for 14 weeks, six patients with actively replicating chronic hepatitis $\mathrm{C}$ for whom an anti-TNF-alpha treatment had been initiated for an associated rheumatoid arthritis. MC appeared in two of the six patients, and it persisted in two others. No patient developed any new signs of autoimmunity. HCV viraemia remained unchanged. However, these data indicate that TNF antagonists may favor emergence of $\mathrm{MC}$ in such patients. For all the reasons described above, the use of anti-TNF-alpha biologics is not advisable in patients with small-vessel vasculitides.

\section{Rituximab}

Unlike ant-TNF-alpha, the biologic RTX apparently shows the best efficacy in small-vessel vasculitis; RTX is an anti-CD20 chimeric monoclonal antibody. One of the first reports ${ }^{48}$ was about the successful, compassionate use of RTX in a patient with chronic, relapsing C-ANCA-associated WG. The patient initially responded to treatment with glucocorticoids and CYC. However, bone marrow toxicity during CYC treatment of a relapse precluded its further use. Azathioprine and mycophenolate mofetil treatment had failed to maintain remission of the WG, and MTX was contraindicated. The patient was given four $375 \mathrm{mg} / \mathrm{m}^{2} \mathrm{RTX}$ infusions and high-dose glucocorticoids. Complete remission was associated with the disappearance of B-lymphocytes and C-ANCA. Glucocorticoid treatment was then discontinued. Eight months after the second course of RTX (18 months after the first course), the patient's WG had remained in complete remission. The authors concluded that elimination of B-cells by RTX therapy might prove an effective and safe new treatment modality for AAV.

In a subsequent case report, ${ }^{49}$ a 26 -year-old man with two relapses of WG was treated with a single standard course of RTX while continuing steroids and mycophenolate. After 4 months, RTX led to the resolution of pulmonary lesions and caused rapid normalization of elevated anti-PR3. There were no side effects from RTX reported.

In another study ${ }^{50}$ two women with myeloperoxidaseANCA-positive MPA and seven patients (five men and two women) with proteinase 3-ANCA-positive WG who were resistant to conventional therapy or who had repeatedly relapsed after cessation of CYC were treated with intravenous infusions of RTX once a week, two times (in three cases) or four times (in six cases). Eight of nine patients responded completely, and one case partially responded. Minor relapse in the nose occurred in two cases. No adverse events or major infections were noted.

In another case, a 42-year-old Caucasian woman who had been diagnosed with WG 15 years ago with end-stage renal failure was described. ${ }^{51}$ She suffered from continuous relapses involving pulmonary hemorrhage, and treatment became increasingly difficult. Symptoms resolved soon after a single administration of low-dose RTX.

Note that in 2011, the year that subtypes of AAV were officially renamed according to key pathological characteristics, important progress was made not only in differentiating these subtypes, but also in understanding - and treating - their eponymous manifestations. ${ }^{52}$

In a retrospective study, ${ }^{53}$ the RTX tolerance of patients who had received at least two RTX maintenance infusions was analyzed. Identified were 28 patients (four with MPA and 24 with GPA; median age 55.5 years [range 18-78]; $17[60 \%]$ males) who received a median of four (range $2-10$ ) 
RTX maintenance infusions, with median follow-up of 38 months (range 21-97) since diagnosis or last flare. None experienced an RTX infusion-related adverse event. Fifteen patients (among the 21 with available data) had hypogammaglobulinemia (predominantly $\operatorname{IgM}$ ) prior to their last RTX maintenance infusion. Three had infectious events (one cutaneous abscess, one otitis, and one fatal case of H1N1 flu). Two suffered pulmonary relapses shortly before a planned RTX maintenance infusion (both had increased antineutrophil cytoplasmic antibody levels), and one had CD19+ lymphocyte reconstitution. The conclusion of this study was that RTX maintenance therapy was well tolerated but did not completely prevent relapses or persistent "grumbling" disease.

However, a recent cohort study, ${ }^{54}$ involving more than 200 patients and trials focused on RTX use for patients with refractory GPA and MPA, showed that RTX was not inferior to CYC for the induction of remission in severe GPA and MPA. In particular, the RAVE trial further showed that RTX was superior to CYC for patients with severe disease relapses. In addition, reports are emerging on the use of RTX for remission maintenance in chronically relapsing patients. All these studies underline the fact that RTX is the first proven alternative to CYC for remission induction in severe GPA and MPA. RTX is the preferred agent for patients presenting with severe disease flares, and its use has become the de facto standard of care for patients with chronically relapsing refractory GPA.

In a further study, ${ }^{55} 43$ patients with refractory GPA received at least two courses of RTX. All had remission of the disease during the depletion of B-cells, and the median time to the return of B-cells was 8.5 months. Relapses occurred in all patients after the reconstitution of B-cells, and these relapses were accompanied or preceded by an increase in ANCA levels. Infusion related adverse events occurred in 16 patients. During the period of B-cell depletion, 30 infections requiring antimicrobial therapy were recorded. From this study, RTX appears to be effective and safe for the induction and maintenance of remission in patients with relapsing GPA. Repeated B-lymphocyte depletion seems to be associated with low risk of infections.

RTX appears to be effective also in CSS. CSS is usually considered a Th2-mediated disease, but Th1 and Th17 responses might also play a role. Corticosteroids, often in combination with cytotoxic agents, comprise standard therapy. However, a number of patients appear to be resistant to treatment, and there is a need for more effective regimens. B-cell depletion may be an effective treatment option for CSS.

A single-center, open-label pilot study ${ }^{56}$ using RTX $\left(375 \mathrm{mg} / \mathrm{m}^{2} /\right.$ week $\left.\times 4\right)$ for the induction of remission in CSS patients with renal involvement was carried out. Patients were eligible if they were untreated, had failed glucocorticoid therapy, or had failed glucocorticoid dose reductions because of disease relapses. Only three patients were enrolled. All achieved the primary end point of renal remission within the first 3 months and remained in renal remission during the year following RTX treatment. One patient experienced a nonrenal relapse (eye and joint involvement) at 6 months, coinciding with the reconstitution of CD19+ cells and eosinophilia. He was retreated with RTX, achieving remission within 6 weeks. No major adverse effects were recorded.

Excellent results have also been obtained by the use of RTX in MC. Immune-induced B-lymphocyte expansion represents the underlying pathological alteration frequently triggered by $\mathrm{HCV}$ infection.

Fifteen consecutive patients with type II MC (HCV-related in 12 of 15) were treated with RTX, $375 \mathrm{mg} / \mathrm{m}^{2}$ intravenously weekly for 4 weeks. Only medium- to low-dose steroids were allowed. All patients had active disease that was poorly controlled or difficult to manage with previous treatments, including corticosteroids in all cases. RTX proved effective on skin vasculitis manifestations (ulcers, purpura, and urticaria), subjective symptoms of peripheral neuropathy, low-grade B-cell lymphoma, arthralgias, and fever. Nephritis of recent onset went into remission in one case. Laboratory-increased C4 was associated with the clinical efficacy. Treatment was well tolerated, with no infectious complications. ${ }^{57,58}$

In a multicenter study, ${ }^{59}$ the effects of RTX in a large series of patients with active MC was evaluated. A significant clinical improvement was observed in a relevant percentage of cases, regardless the presence or absence of associated HCV infection. Importantly, cryoglobulinemic nephropathy, observed in 38 patients, significantly improved in $95 \%$ of cases. A complete remission of abdominal vasculitis was also observed in one patient. The safety of RTX was confirmed by the small number of side effects recorded during the 6-month follow-up. According to these results, RTX may be regarded as a useful and safe pathogenetic treatment of cryoglobulinemic vasculitis. ${ }^{59,60}$ From analysis of these and other published studies, RTX appears a very powerful tool for the treatment of small-vessel vasculitides. Further controlled studies are needed to reinforce the current favorable data.

\section{Other biologics}

Other biologics are currently available for the treatment of either inflammatory rheumatic diseases or other autoimmune diseases. These include golimumab (an anti-TNF-alpha agent) and abatacept (a fusion protein 
including the extracellular domain of CTLA-4 that inhibits the costimulation of $\mathrm{T}$ cells). Another is ustekinumab, an anti-IL-12 and IL-23 monoclonal antibody that is licensed for the treatment of plaque psoriasis but which is also investigated for other indications such as psoriatic arthritis, Crohn's disease, and relapsing/remitting multiple sclerosis. Yet another is alefacept, which blocks costimulatory molecule LFA-3/CD2 interaction, inhibiting both CD4+ and CD8+ T-cell activation.

Regarding golimumab, very few and apparently conflicting data have been reported. In one study, the use of golimumab was suggested to be efficacious in uveitis and associated ocular vasculitis. ${ }^{61}$ However, Parekh et $\mathrm{l}^{62}$ reported the onset of $\mathrm{WG}$ in a patient treated with golimumab for rheumatoid arthritis.

Abatacept has recently been proven effective in cases of rheumatoid vasculitis. ${ }^{63}$ The rationale of abatacept use in vasculitides is based on both increased expression of CTLA-4 by B- and T-cells ${ }^{64}$ and polymorphisms in the CTLA-4 gene observed in WG. ${ }^{65}$ However, additional studies are needed to assess the actual clinical usefulness of abatacept in vasculitis-syndrome therapy.

No data are currently available on the use of ustekinumab and alefacept in the treatment of vasculitides. An issue that must also be addressed is that in the near future, many new therapeutic agents for treating inflammatory rheumatic diseases, and possibly vasculitides, will be available, including the so-called small molecules. In this regard, particular attention should be focused on the possibility of targeting proinflammatory Th17 cells, which play a pivotal role in the pathogenesis of most autoimmune diseases. ${ }^{66}$

\section{Conclusion}

Biologics used for treating moderate to severe inflammatory rheumatic diseases may have a pivotal role in the treatment of systemic vasculitides that have not responded to standard treatment or that cannot be treated with common immunosuppressants because of their side effects. The different types of vasculitides seem to respond to different biologics. In particular, TCZ appears to be particularly effective in large- and medium-vessel vasculitides, whereas RTX is effective in small-vessel vasculitides. It should be considered, however, whether the relevant findings are mainly from single case studies or small uncontrolled trials, and whether their use is still off-label. Large, randomized, prospective, double-blinded trials are warranted, to ascertain both the safety and efficacy of the currently available biologics in the treatment of refractory vasculitides. Finally, but not less importantly, biologics are very expensive drugs, and this must also be taken into account in practice. ${ }^{67}$

\section{Disclosure}

The author reports no conflict of interest in this work.

\section{References}

1. Falk RJ, Gross WL, Guillevin L, et al. Granulomatosis with polyangiitis (Wegener's): an alternative name for Wegener's granulomatosis. Arthritis Rheum. 2011;63(4):863-864.

2. Fries JF, Hunder GG, Bloch DA, et al. The American College of Rheumatology 1990 criteria for the classification of vasculitis. Summary. Arthritis Rheum. 1990;33(8):1135-1136.

3. Jennette JC, Falk RJ, Andrassy K, et al. Nomenclature of systemic vasculitides. Proposal of an international consensus conference. Arthritis Rheum. 1994;37(2):187-192.

4. Cutolo M, Montecucco CM, Cavagna L, et al. Serum cytokines and steroidal hormones in polymyalgia rheumatica and elderly-onset rheumatoid arthritis. Ann Rheum Dis. 2006;65(11):1438-1443.

5. Hernandez-Rodriguez J, Garcia-Martinez A, Casademont J, et al. A strong initial systemic inflammatory response is associated with higher corticosteroid requirements and longer duration of therapy in patients with giant-cell arteritis. Arthritis Rheum. 2002;47(1): 29-35.

6. Aikawa NE, Pereira RM, Lage L, Bonfa E, Carvalho JF. Anti-TNF therapy for polymyalgia rheumatica: report of 99 cases and review of the literature. Clin Rheumatol. 2012;31(3):575-579.

7. Bejerano C, Blanco R, Gonzalez-Vela C, et al. Polymyalgia rheumatica as presenting manifestation of vasculitis involving the lower extremities in a patient with ulcerative colitis. Clin Exp Rheumatol. 2012; 30(1 Suppl 70):S110-S113.

8. Bejerano C, Blanco R, Gonzalez-Vela C, Aguero R, Carril JM, Gonzalez-Gay MA. Refractory polymyalgia rheumatica as presenting manifestation of large-vessel vasculitis associated to sarcoidosis. Successful response to adalimumab. Clin Exp Rheumatol. 2012;30(1 Supp1 70): S94-S97.

9. Comarmond C, Plaisier E, Dahan K, et al. Anti TNF-alpha in refractory Takayasu's arteritis: cases series and review of the literature. Autoimmun Rev. 2012;11(9):678-684.

10. Osman M, Aaron S, Noga M, Yacyshyn E. Takayasu's arteritis progression on anti-TNF biologics: a case series. Clin Rheumatol. 2011; 30(5):703-706.

11. Oishi T, Fujieda M, Shiraishi T, et al. Infliximab treatment for refractory Kawasaki disease with coronary artery aneurysm. Circ J. 2008;72(5): 850-852.

12. Burns JC, Mason WH, Hauger SB, et al. Infliximab treatment for refractory Kawasaki syndrome. J Pediatr. 2005;146(5):662-667.

13. Hirano T, Yasukawa K, Harada H, et al. Complementary DNA for a novel human interleukin (BSF-2) that induces B lymphocytes to produce immunoglobulin. Nature. 1986;324(6092):73-76.

14. Bettelli E, CarrierY, Gao W, et al. Reciprocal developmental pathways for the generation of pathogenic effector TH17 and regulatory T cells. Nature. 2006;441(7090):235-238.

15. Nemeth E, Rivera S, Gabayan V, et al. IL-6 mediates hypoferremia of inflammation by inducing the synthesis of the iron regulatory hormone hepcidin. J Clin Invest. 2004;113(9):1271-1276.

16. Sardella G, Mariani P, D'Alessandro M, et al. Early elevation of interleukin1 beta and interleukin-6 levels after bare or drug-eluting stent implantation in patients with stable angina. Thromb Res. 2006;117(6):659-664.

17. Emilie D, Liozon E, Crevon MC, et al. Production of interleukin 6 by granulomas of giant cell arteritis. Hum Immunol. 1994;39(1):17-24.

18. Lecron JC, Roblot P, Chevalier S, et al. High circulating leukaemia inhibitory factor (LIF) in patients with giant cell arteritis: independent regulation of LIF and IL-6 under corticosteroid therapy. Clin Exp Immunol. 1993;92(1):23-26. 
19. Roche NE, Fulbright JW, Wagner AD, Hunder GG, Goronzy JJ, Weyand CM. Correlation of interleukin-6 production and disease activity in polymyalgia rheumatica and giant cell arteritis. Arthritis Rheum. 1993;36(9):1286-1294.

20. Corrigall VM, Dolan AL, Dasgupta B, Panayi GS. The sequential analysis of T lymphocyte subsets and interleukin-6 in polymyalgia rheumatica patients as predictors of disease remission and steroid withdrawal. $\mathrm{Br}$ J Rheumatol. 1997;36(9):976-980.

21. Uddhammar A, Sundqvist KG, Ellis B, Rantapaa-Dahlqvist S. Cytokines and adhesion molecules in patients with polymyalgia rheumatica. $\mathrm{Br} J$ Rheumatol. 1998;37(7):766-769.

22. Straub RH, Gluck T, Cutolo M, et al. The adrenal steroid status in relation to inflammatory cytokines (interleukin-6 and tumour necrosis factor) in polymyalgia rheumatica. Rheumatology (Oxford). 2000; 39(6):624-631.

23. Cutolo M, Straub RH, Foppiani L, et al. Adrenal gland hypofunction in active polymyalgia rheumatica. Effect of glucocorticoid treatment on adrenal hormones and interleukin 6. J Rheumatol. 2002;29(4): 748-756.

24. Roblot P, Morel F, Lelievre E, Gascan H, Wijdenes J, Lecron JC. Serum cytokine and cytokine receptor levels in patients with giant cell arteritis during corticotherapy. J Rheumatol. 1996;23(2):408-410.

25. Nishimoto N, Nakahara H, Yoshio-Hoshino N, Mima T. Successful treatment of a patient with Takayasu arteritis using a humanized anti-interleukin-6 receptor antibody. Arthritis Rheum. 2008;58(4): 1197-1200.

26. Unizony S, Arias-Urdaneta L, Miloslavsky E, et al. Tocilizumab for the treatment of large-vessel vasculitis (giant cell arteritis, takayasu arteritis) and polymyalgia rheumatica. Arthritis Care Res (Hoboken). Epub 2012 Jun 5.

27. Bredemeier M, Rocha CM, Barbosa MV, Pitrez EH. One-year clinical and radiological evolution of a patient with refractory Takayasu's arteritis under treatment with tocilizumab. Clin Exp Rheumatol. 2012; 30(1 Suppl 70):S98-S100.

28. Salvarani C, Magnani L, Catanoso MG, et al. Rescue treatment with tocilizumab for Takayasu arteritis resistant to TNF-alpha blockers. Clin Exp Rheumatol. 2012;30(1 Suppl 70):S90-S93.

29. Christidis D, Jain S, Das Gupta B. Successful use of tocilizumab in polymyalgic onset biopsy positive GCA with large vessel involvement. BMJ Case Rep. 2011; doi:10.1136/bcr.04.2011.4135.

30. Hagihara K, Kawase I, Tanaka T, Kishimoto T. Tocilizumab ameliorates clinical symptoms in polymyalgia rheumatica. J Rheumatol. 2010; 37(5):1075-1076.

31. Grillo-Lopez AJ. Rituximab: an insider's historical perspective. Semin Oncol. 2000;27(6 Suppl 12):S9-S16.

32. Einfeld DA, Brown JP, Valentine MA, Clark EA, Ledbetter JA. Molecular cloning of the human $\mathrm{B}$ cell CD20 receptor predicts a hydrophobic protein with multiple transmembrane domains. EMBOJ. 1988;7(3):711-717.

33. Demidem A, Lam T, Alas S, Hariharan K, Hanna N, Bonavida B. Chimeric anti-CD20 (IDEC-C2B8) monoclonal antibody sensitizes a B cell lymphoma cell line to cell killing by cytotoxic drugs. Cancer Biother Radiopharm. 1997;12(3):177-186.

34. Golay J, Zaffaroni L, Vaccari T, et al. Biologic response of B lymphoma cells to anti-CD20 monoclonal antibody rituximab in vitro: CD55 and CD59 regulate complement-mediated cell lysis. Blood. 2000;95(12): 3900-3908.

35. Shan D, Ledbetter JA, Press OW. Signaling events involved in anti-CD20-induced apoptosis of malignant human B cells. Cancer Immunol Immunother. 2000;48(12):673-683.

36. Johnson P, Glennie M. The mechanisms of action of rituximab in the elimination of tumor cells. Semin Oncol. 2003;30(1 Suppl 2): S3-S8.

37. Uchida J, Hamaguchi Y, Oliver JA, et al. The innate mononuclear phagocyte network depletes B lymphocytes through Fc receptordependent mechanisms during anti-CD20 antibody immunotherapy. J Exp Med. 2004;199(12):1659-1669.
38. Anolik JH, Barnard J, Cappione A, et al. Rituximab improves peripheral B cell abnormalities in human systemic lupus erythematosus. Arthritis Rheum. 2004;50(11):3580-3590.

39. Liu CY, Chandrasekar PH, Masood A, Schiffer CA. Adherence to hepatitis $\mathrm{B}$ screening and prophylactic lamivudine for prevention of rituximab-associated hepatitis B reactivation. J Oncol Pharm Pract. Epub 2012 May 25.

40. Sagnelli E, Pisaturo M, Sagnelli C, Coppola N. Rituximab-based treatment, HCV replication, and hepatic flares. Clin Dev Immunol. Epub 2012 Aug 5.

41. Hoyer BF, Mumtaz IM, Loddenkemper K, et al. Takayasu arteritis is characterised by disturbances of $\mathrm{B}$ cell homeostasis and responds to B cell depletion therapy with rituximab. Ann Rheum Dis. 2012;71(1):75-79.

42. Sauvaget E, Bonello B, David M, Chabrol B, Dubus JC, Bosdure E. Resistant Kawasaki disease treated with anti-CD20. J Pediatr. 2012;160(5):875-876.

43. Ribeiro E, Cressend T, Duffau P, et al. Rituximab Efficacy during a refractory polyarteritis nodosa flare. Case Report Med. 2009;2009:738293.

44. Neel A, Masseau A, Hervier B, et al. Life-threatening hepatitis C virus-associated polyarteritis nodosa successfully treated by rituximab. J Clin Rheumatol. 2011;17(8):439-441.

45. Silva F, Seo P, Schroeder DR, et al. Solid malignancies among etanercept-treated patients with granulomatosis with polyangiitis (Wegener's): long-term followup of a multicenter longitudinal cohort. Arthritis Rheum. 2011;63(8):2495-2503.

46. Franceschini D, Del Porto P, Piconese S, et al. Polyfunctional type-1, -2 , and $-17 \mathrm{CD} 8(+) \mathrm{T}$ cell responses to apoptotic self-antigens correlate with the chronic evolution of hepatitis C virus infection.; PLoS Pathog. 2012;8(6):e1002759.

47. Vauloup C, Krzysiek R, Greangeot-Keros L, et al. Effects of tumor necrosis factor antagonist treatment on hepatitis C-related immunological abnormalities. Eur Cytokine Netw. 2006;17(4):290-293.

48. Specks U, Fervenza FC, McDonald TJ, Hogan MC. Response of Wegener's granulomatosis to anti-CD20 chimeric monoclonal antibody therapy. Arthritis Rheum. 2001;44(12):2836-2840.

49. Kallenbach M, Duan H, Ring T. Rituximab induced remission in a patient with Wegener's granulomatosis. Nephron Clin Pract. Epub 2005;99(3):c92-c96.

50. Eriksson P. Nine patients with anti-neutrophil cytoplasmic antibody-positive vasculitis successfully treated with rituximab. J Intern Med. 2005;257(6):540-548.

51. Hermle T, Goestemeyer AK, Sweny P, Burns A. Successful therapeutic use of rituximab in refractory Wegener's granulomatosis after renal transplantation. Clin Nephrol. 2007;68(5):322-326.

52. Gadola SD, Gross WL. Vasculitis in 2011: the renaissance of granulomatous inflammation in AAV. Nat Rev Rheumatol. 2012;8(2):74-76.

53. Roubaud-Baudron C, Pagnoux C, Meaux-Ruault N, et al. Rituximab maintenance therapy for granulomatosis with polyangiitis and microscopic polyangiitis. J Rheumatol. 2012;39(1):125-130.

54. Cartin-Ceba R, Fervenza FC, Specks U. Treatment of antineutrophil cytoplasmic antibody-associated vasculitis with rituximab. Curr Opin Rheumatol. 2012;24(1):15-23.

55. Cartin-Ceba R, Golbin JM, Keogh KA, et al. Rituximab for remission induction and maintenance in refractory granulomatosis with polyangiitis (Wegener's): a single-center ten-year experience. Arthritis Rheum. Epub 2012 Jun 21.

56. Cartin-Ceba R, Keogh KA, Specks U, Sethi S, Fervenza FC. Rituximab for the treatment of Churg-Strauss syndrome with renal involvement. Nephrol Dial Transplant. 2011;26(9):2865-2871.

57. Quartuccio L, Soardo G, Romano G, et al. Rituximab treatment for glomerulonephritis in HCV-associated mixed cryoglobulinaemia: efficacy and safety in the absence of steroids. Rheumatology (Oxford). 2006;45(7):842-846.

58. Zaja F, De Vita S, Mazzaro C, et al. Efficacy and safety of rituximab in type II mixed cryoglobulinemia. Blood. 2003;101(10):3827-3834. 
59. De Vita S, Quartuccio L, Isola M, et al. A randomized controlled trial of rituximab for the treatment of severe cryoglobulinemic vasculitis. Arthritis Rheum. 2012;64(3):843-853.

60. Ferri C, Cacoub P, Mazzaro C, et al. Treatment with rituximab in patients with mixed cryoglobulinemia syndrome: results of multicenter cohort study and review of the literature. Autoimmun Rev. 2011;11(1): $48-55$.

61. Cordero-Coma M, Salom D, Diaz-Llopis M, Lopez-Prats MJ, Calleja S. Golimumab for uveitis. Ophthalmology. 2011;118(9):1892-1894.

62. Parekh K, Ching D, Rahman MU, Stamp LK. Onset of Wegener's granulomatosis during therapy with golimumab for rheumatoid arthritis: a rare adverse event? Rheumatology (Oxford). 2010;49(9):1785-1787.

63. Fujii W, Kohno M, Ishino H, et al. The rapid efficacy of abatacept in a patient with rheumatoid vasculitis. Mod Rheumatol. 2012;22(4): $630-634$.
64. Steiner K, Moosig F, Csernok E, et al. Increased expression of CTLA-4 (CD152) by T and B lymphocytes in Wegener's granulomatosis. Clin Exp Immunol. 2001;126(1):143-150.

65. Giscombe R, Wang X, Huang D, Lefvert AK. Coding sequence 1 and promoter single nucleotide polymorphisms in the CTLA-4 gene in Wegener's granulomatosis. J Rheumatol. 2002;29(5):950-953.

66. Huh JR, Littman DR. Small molecule inhibitors of RORgammat: targeting Th17 cells and other applications. Eur J Immunol. 2012; 42(9):2232-2237.

67. Schabert VF, Watson C, Gandra SR, Goodman S, Fox KM, Harrison DJ. Annual costs of tumor necrosis factor inhibitors using real-world data in a commercially insured population in the United States. JMed Econ. 2012;15(2):264-275.

\section{Publish your work in this journal}

Biologics: Targets \& Therapy is an international, peer-reviewed journal focusing on the patho-physiological rationale for and clinical application of Biologic agents in the management of autoimmune diseases, cancers or other pathologies where a molecular target can be identified. This journal is indexed on PubMed Central, CAS, EMBase, Scopus

\section{Dovepress}

and the Elsevier Bibliographic databases. The manuscript management system is completely online and includes a very quick and fair peerreview system, which is all easy to use. Visit http://www.dovepress com/testimonials.php to read real quotes from published authors. 